\title{
Turismo y crisis en España y Cataluña, balance provisional de un difícil 2012
}

\section{Tourism and crisis in Spain and Catalonia, provisional balance of a difficult 2012}

\author{
Lluís Mundet i Cerdan (MUNDET, Ll.)
}

RESUMEN - Este breve artículo de opinión analiza el comportamiento del sector turístico en España, con especial mención a Cataluña que se ha convertido en el primer destino turístico del estado español. Así mismo se pone de manifiesto la importancia y resistencia del sector turístico ante la grave crisis económica que afecta Europa y, muy especialmente al estado español.

Palabras clave: Turismo; Temporada 2012; Crisis; Cataluña; España

ABSTRACT - This short note analyses the behavior of the tourist sector in Spain, with special attention to Catalonia which is right now the main tourist destination in Spain. At the same time, it's shown the importance and resilience of the tourist sector when confronting a severe economic crisis as is this one affecting the whole of Europe and, especially to Spain.

Key words: Tourism; 2012 Season; Crisis; Catalonia; Spain

\footnotetext{
* Membro do Comitê Científico da Revista "Turismo e Sociedade" desde junho de 2012. Formação: Licenciatura en Filosofía y Letras (Geografía) pela Universidad Autónoma de Barcelona (UAB), Master in Leisure and Tourism Studies pela Universidad de Gante (Flandes, Bélgica), Doctorado en Geografía pela Universidad de Girona (UdG). Profesor Titular da Facultad de Turismo da Universidad de Girona (UdG). Endereço para correspondência: Facultat de Turisme, Universitat de Girona, Plaça Ferrater Mora 1, 17071 Girona, Catalunya (Espanya). Email: 1luis.mundet@udg.cat
} 


\section{INTRODUCCIÓN}

El sector del turismo, responsable de un 11\% del PIB y también de un 11 de la ocupación en España, a pesar de la grave crisis económica que, desde el 2008, sacude las economías europeas y, muy especialmente la española y catalana (con un índice de paro del 25\%) sigue dando oxígeno a la economía y, tal como demuestran las cifras de ocupación del verano, anticipan una temporada turística 2012 que pueden marcar nuevos récords históricos de ingresos y llegadas de turistas internacionales.

\section{CATALUÑA PRIMER DESTINO TURÍSTICO DEL ESTADO ESPAÑOL}

España recibió 40,7 millones de turistas internacionales en los ocho primeros meses del año, lo que supone un 3,6\% más respecto al mismo periodo de 2011, consiguiendo un nuevo máximo histórico.

La cifra de visitantes extranjeros bate así el anterior máximo de esta serie, de 7,7 millones, registrado en julio pasado, y contribuye a lograr un verano récord en llegada de turistas, con 15,6 millones en los dos meses de temporada alta (julio y agosto). Así pues, parece ser que 2012 será un año de grandes récords.

Son datos de la Encuesta de Movimientos Turísticos en Frontera (Frontur) difundida por el Ministerio de Industria, Energía y Turismo. Los principales mercados emisores han sido Reino Unido, Francia y Alemania, aunque Rusia fue el país que mayor incremento registró, con un alza del 37\%.

Catalunya, con estas cifras, consolida su posición como principal destino turístico del estado español en agosto, con un aumento del 14,7\% en la llegada de turistas y 255.000 turistas más, en consonancia con la positiva evolución llevada a cabo durante todo el año. Los mercados británico y francés impulsaron este mayor flujo de llegadas en gran medida. Por su parte, Baleares se posicionó en el octavo mes del año como segundo destino nacional, e incrementó por cuarto mes consecutivo el número de turistas, hasta 1,88 millones de visitantes, un 2,8\% más, gracias al aumento de británicos y franceses. 
Andalucía, tras siete meses consecutivos de caídas, aumentó un 9,6\%, hasta más de un millón de visitantes, el número de llegadas gracias a la mayor afluencia desde Francia. Asimismo, Canarias mantiene prácticamente el mismo volumen de llegadas $(+0,1 \%)$ de hace un año, después de recibir a 822.000 turistas procedentes del exterior, que crecieron levemente. La Comunidad Valenciana tuvo también un ligero avance del 0,9\% con 751.000 turistas. Por contra, la Comunidad de Madrid retrocedió casi un 30\% en el número de turistas extranjeros, debido al gran incremento registrado en agosto de 2011 por la Jornada Mundial de la Juventud y la menor llegada de turistas italianos.

Si cambiamos la escala temporal del análisis y analizamos la evolución del número de turistas no sólo en agosto sino, desde principios de año. Catalunya, con un aumento del $12,1 \%$, captó el mayor porcentaje de visitantes extranjeros, un 25,5\% del total de las llegadas hasta agosto, lo que se tradujo en 10,39 millones de turistas recibidos. Baleares, en segundo lugar, recibió 7,7 millones de turistas, un 2,4\% más, con el 19,1\% del total, seguida de Canarias, con 6,6 millones de visitantes $(-0,1 \%)$ y Andalucía, con un 2,5\% menos de visitantes, hasta 5,3 millones de turistas extranjeros. La Comunidad Valenciana recibió 3,7 millones de turistas (-0,8\%), mientras que la Comunidad de Madrid aumentó un 4,7\% sus visitantes extranjeros, hasta 3 millones de turistas.

\subsection{FRANCIA IMPULSA LAS VISITAS}

El mercado ruso ha sido el que ha experimentado el crecimiento más abultado al llegar un 47,5\% más en agosto que el mismo mes de 2011.

Reino Unido, Francia y Alemania fueron los principales mercados emisores en agosto. Los franceses han sido los que más han impulsado el crecimiento este mes, con un significativo avance del $17,5 \%$ que beneficia a todas las comunidades principales, especialmente Cataluña. El Reino Unido protagonizó un incremento del 4,7\%, volviendo así a la senda del crecimiento, tras la estabilidad mostrada en el mes de julio, con Cataluña y Baleares como principales comunidades receptoras de este mayor flujo. El número de alemanes retrocedió un 4,3\%. Los países nórdicos mantuvieron la tendencia creciente de los meses anteriores, concentrando en Andalucía y Baleares gran parte de la subida. Entre el resto de mercados, destaca por su crecimiento Rusia, con un significativo avance del $47,5 \%$. 
Por vía de acceso el aeropuerto registra en agosto un incremento del 2,7\%, inferior al de los últimos meses, mientras que la carretera mantiene la línea de subidas, protagonizando un avance del 9,6\%, que le lleva a ser la vía de entrada que más contribuye al crecimiento este mes.

El alojamiento hotelero recibe en agosto un 8,9\% más de turistas que hace un año, mientras el alojamiento no hotelero crece un $0,2 \%$. Los turistas que contratan paquete turístico caen por segundo mes consecutivo, con una bajada del 2,7 \%, mientras que los que no optan por esta modalidad crecen un $8,2 \%$.

\subsection{EL AEROPUERTO DE BARCELONA SUPERA AL DE MADRID COMO PRINCIPAL PUNTO DE ORIGEN Y DESTINO DE PASAJEROS}

En consonancia con estas cifras y con el hecho de que Cataluña se haya convertido en el primer destino turístico del estado español, el aumento acumulado en el aeropuerto de Barcelona se ha visto favorecido por el tráfico intercontinental, que ha crecido un 4,1\%. El Aeropuerto de El Prat ha superado este año por primera vez a Barajas como principal punto de origen y destino de pasajeros, con 17,5 millones entre enero y julio en Barcelona frente a 16,7 millones en Madrid, según datos de la Cámara de Comercio de Barcelona.

El aeropuerto catalán superó en marzo por primera vez a Barajas en vuelos de origen y destino - sin tener en cuenta los vuelos de conexión - y ha mantenido esta tendencia. El aumento acumulado en Barcelona se ha visto favorecido por el tráfico intercontinental, que ha crecido un $4,1 \%$, y el europeo, que ha aumentado un $12,1 \%$ respecto al mismo periodo del año pasado.

\section{CONCLUSIONES}

El sector económico del turismo se ha convertido en uno de los pocos puntales sólidos de las maltrechas economías española y catalana. El turismo y el sector exportador (muy especialmente en el caso de Cataluña) son de los pocos sectores 
económicos que resisten e incluso mejoran su comportamiento en este ya quinto año de crisis económica.

Así pues, el sector turístico se consolida como un elemento estructural y definitorio del modelo económico de la península.

Destaca en especial el comportamiento y el liderazgo turístico de Cataluña dentro del estado español, cosa que equivale a decir, Barcelona. Ciudad que sólo el año 2011 ya tuvo 7,4 millones de turistas y que se ha traducido en un mayor dinamismo de su aeropuerto quien, a pesar de contar con pocas conexiones internacionales y tampoco ser un hub internacional (España, Iberia y AENA, sólo aceptaron que lo fuera el aeropuerto de Madrid - Barajas) por primera vez y, resultado de este extraordinario comportamiento turístico, ha sobrepasado en número de llegadas al aeropuerto de Madrid.

Resumiendo, el turismo continua demostrando que, es uno de los sectores económicos más resistentes e impermeables a cualquier tipo de crisis económica, por más fuerte y duradera que sea la misma. Y, en muchos casos, es de los pocos sectores que ayudan a paliar los mismos efectos de esta crisis, enfrente de otros sectores económicos considerados más "serios".

\section{REFERÊNCIAS}

AENA aeropuertos (Fecha acceso 21/09/2012): http://estadisticas.aena.es

Estadísticas de turismo en Barcelona y provincia 2011. Barcelona Turisme (Fecha acceso 23/09/2012: http://professional.barcelonaturisme.com/imgfiles/estad/Est2011.pdf

Nota de Coyuntura (Agosto 2012). Frontur, Movimientos turísticos en fronteras. IET (Fecha acceso 22/09/2012): www.iet.tourspain.es 